by a simple chemical test. The first division is made on the basis of differences of grain (granularity) into three classes. These are divided according as the rock in question is porphyritic or non-porphyritic. Further division is made, chiefly upon differences of mineral composition, into a few broad groups which are designated by familiar rock names (granite, diorite, etc.) firmly fixed in petrological literature by long usage. The more important varieties falling under these various groups or kinds of rock, but which for microscopical or other reasons have received special names from petrographers, are referred to in appropriate places, so that the significance of such names when encountered can be easily found by reference to the book. Among the names adopted for the rock groups, it may be noted that dolerite has been retained, very wisely it seems, to designate those granular, igneous rocks, with predominant ferro-magnesian minerals but in which it is not possible to tell positively just what ferro-magnesian mineral is present. This group will therefore include much that is commonly referred to as diabase. Felsite (resp. felsite-porphyry) is used for those nearly or entirely dense rocks, light in color, and generally highly feldspathic in character, while basalt (resp. basalt-porphyry) covers those dense, dark-colored, igneous rocks, for the most part ferro-magnesian in character. It will be noted that both of these terms, felsite and basalt, have been given a broader meaning than is customary in books covering a somewhat similar field. For example, dacites and most andesites fall under the head of felsite. Directions, however, for recognizing such varieties when it is possible to do so macroscopically, are given. The classification is summarized in a convenient table on page 202.

While some teachers will doubtless wish to make some minor additions to the scheme of classification in their class-room work, the scheme as a whole appears so sane, simple and practical that it can not fail to meet with general approval, and it is to be hoped that it will also come shortly into general use. In such an event it would be a strong influence toward uniformity and simplicity of practise among field workers in geology and petrology.

In Chapter VII. we find the descriptions of individual kinds of rock treated under such appropriate headings as: Mineral Composition; General Properties; Chemical Composition (the latter illustrated by a few wellchosen analyses); Occurrence and Alteration. Thus while the descriptions furnish one with data useful for the recognition of the rock in the field or laboratory, they also furnish in a most satisfactory manner what might be termed the Natural History of the rock.

With so excellent a manual available as a basis for petrological study it is to be hoped that it may be substituted for the dry and generally uninteresting lecturing so common in petrological laboratories, as well as for the too numerous laboratory guides and notes of inferior quality, and thus promote a general improvement in petrological teaching.

In conclusion it may be said that the book is conspicuous by reason of its typographical excellence and for the superior quality of the illustrations which admirably illustrate the text. Charles H. Warren

Massachusetts Institute of TeChNoLogy, Boston, Mass.

Die Pendulationstheorie. Von Dr. HeInrich Simroth, Professor an der Universität Leipzig. Octavo, S. 564, Karten 27. Leipzig, Konrad Grethlein's Verlag, 1907. Pr. brosch, M. 12.

Theories of polar pendulation, based on geological or geographical considerations, have been proposed independently in the past few years by two investigators, one ${ }^{1}$ an engineer, another ${ }^{2}$ a geologist. To Professor Simroth alone among biologists, however, does the idea seem to have appealed as worthy of attention for its possible value in explaining the facts of zoogeography.

${ }^{1}$ Paul Reibisch, "Ein Gestaltungsprinzip der Erde," 27 Jahresber. Ver. f. Erdk. zu Dresden, 1901, S. 105-124. II., ibid., 1905, S. 39-53, 2 Karten.

${ }^{2} \mathrm{D}$. Kreichgaur, "Die Aquatorfrage in der Geologie," Steyl, 1902. 
The theory of Reibisch (rather than that of Kreichgaur), which the author has chosen as his working hypothesis, was first suggested to its originator as a tentative explanation of certain puzzling geographical facts. In particular is mentioned that the west coast line of South America becomes higher as one proceeds southward from the equator; and that recent coral reefs in the Pacific are partly in the condition of rising and partly in that of sinking. These differences are explained, according to Reibisch, if in addition to the difference between the rotational and equatorial diameters of the earth $(40 \mathrm{~km}$.), we assume a slow "pendulation" of the globe on an axis approximately perpendicular to the rotational axis, whose poles lie in the vicinity of Ecuador and Sumatra. In consequence of the greater equatorial diameter it follows that as a body of land in pendulation approaches the equator it will tend to be submerged, and that as it approaches the rotational poles it will correspondingly rise. This effect of the swing on land elevation will be greatest along the "Schwingungskreis," a great circle about the earth marking the greatest amplitude of swing. The Schwingungskreis passes through the two rotational poles, traverses the Pacific across its middle, crosses the Scandinavian Peninsula and the continent of Europe southward, and lops off the northwest quarter of Africa. In conformity with this theory the terrane quadrant embracing the North Atlantic, Europe, North Africa, and all of Asia except the east third is supposed now to be in "equatorial pendulation," that is, is nearing the equatorial position in the swing on the Sumatra-Ecuador pole. The same quadrant is assumed to have had a position farther northward in the glacial period, and to have lain farther southward in the Jurassic and Cretaceous. The "South Pacific" quadrant likewise is assumed to be now gradually approaching the equatorial position (in "equatorial phase"); while the "North Pacific" quadrant, embracing also the eastern third of Asia, and North America with the exception of Greenland and the Labrador region, is receding from the equator (in "polar phase"). The "Atlantic-India South" quadrant, ta- king in the bulk of the Indian Ocean, the south Atlantic, lower Africa, and South America below Ecuador, now finds itself approaching the polar phase. The region of the swing-poles themselves is necessarily subject to little swing, and is therefore supposed to have endured in the course of geologic ages little or no large climatic change.

In his general introductory discussion, following the exposition of the mechanics of the Reibisch hypothesis, and dealing in a broad way with the significance of pendulation in the origin and distribution of organisms, Professor Simroth enrolls himself with the adherents of the Kant-Laplace theory and takes no account at all of later theories of earthorigin. It is accordingly assumed that life must have arisen at a time of average higher temperature than prevails at present. On the question of the place of origin of the first organisms the Reibisch theory is regarded happily as broad and flexible enough to cover the requirements of any of the various suppositions that have been made. To the Laplacian and pendulationist it need make little difference whether it is held that life arose on land or in the water, at the rotational poles or in the tropics. The hypothesis of a gradually cooling globe, however, favors the supposition of the origin of life at the poles or on the mountains-these being the most cooled situations at any given time after surface solidification. And with further cooling must begin the pro-tropical migration, for need of warmth, that in time results in the concentration of a large primitive fauna in the tropics (liberally defined), to form the starting point of the succeeding movements which Professor Simroth finds the pendulation theory so helpful in explaining. If the "Urthiere" are already there, so much the better. If not, it is scarcely less easy than necessary to get them there, or at least started in that direction. For the companion assumption that the "great bulk of the most ancient known forms of life have lived, first or last, in the tropics, where they arose, or whither they had been driven by the advancing cold," is of cardinal importance in any endeavor to explain animal distribution in accordance with a principle of 
pendulation. Of the truth of such an assumption it is held that the facts of paleontology, as well as our knowledge of the distribution and relationships of living forms, furnish an encouraging amount of corroborative evidence.

With the two hypotheses of pendulation and a concentration of a primitive fauna in the tropics established or granted, we are all but ready to follow the ensuing movements that are conceived to have determined the manner and direction of the dispersals of the past and of to-day. A circumequatorial movement, away from the vicinity of the swing poles themselves and toward the Schwingungskreis, is all that remains necessary in order to get these populations of old within the "sphere of influence" of the swing. This lateral movement is conceived as practically a logical necessity, those forms of life inhabiting the hot zone, and especially those portions of it with most equable temperature, $i$. e., about the swing-poles, being forced as they increased in numbers to begin an effort to extend their range in a like temperature and so long as no obstacles of the medium or other kind stood in the way. How inevitable are the consequences of pendulation to a "caught" population, in the view of the author, once the preceding suppositions have been allowed, is evident from the following quotation: "An organism that has arisen under the Schwingungskreis [or has migrated there or near there] will as a consequence of pendulation be mechanically removed from its proper climate unless it moves out to the right and left on its own parallel. ... Its distribution thus becomes discontinuous. It will inhabit two separated areas [transversally symmetrical points] which lie one to each side of the Schwingungskreis," the eastward or westward migration only coming to a stop when first a point is reached "which most nearly resembles climatically the original habitat." Among the more salient examples of transversally symmetrical points offered by the author are: the alligator, the sole Asiatic species of which lives in the Yang Tse Kiang, while the nearest related form found elsewhere inhabits the lower Mississippi; the shovel-nosed sturgeons, of Turkestan and the Mississippi Valley; Psephurus and Polyodon; the dipnoans, Lepidosiren and Ceratodus; species of Cryptobranchus, Limulus, Pleurotomaria; points of maximal abundance of landsnails, etc. The map (No. 5) exhibiting the geographical relations of the most striking of these cases of "transversal symmetry" adds much clearness and force to this portion of the text. The predictableness of location of these transversally symmetrical points in the light of a "Pendulations-mechanik" leads the author to observe of the first expedition sent out to search for dipnoans in South America, that the unsuccessful search in the Amazon region was the result of a "false scent" wholly unnecessary had the biologists of those days possessed our present knowledge. Without pendulation "what a keen hypothesis were necessary," he asks, in order to furnish so clear and certain an elucidation of these instances! That all species or faunas caught by the swing should thus move out laterally from the Schwingungskreis and their little (or much) modified descendants so come to occupy such symmetrically situated habitats is too much to be expected and is not a meaning intentionally conveyed by the author. The length of time required for a full pendulation, for example, the interval between the Jurassic and the Tertiary, would seem, for one thing, to leave ample time for such of the forms affected as might choose to remain stationary to adapt themselves to the changed conditions. And, again, as we shall see, the ways in which pendulation may work in influencing the changes and movements of organisms are more than one.

That mode of distribution called by the author "meridial symmetry" is another interesting phenomenon on which light is thrown by the pendulation theory. Thanks to it, the occurrence of closely related forms, for example, in California and Chili and in Japan and Australia need no longer puzzle. "Forms once carried northward with the polar swing, in the next equatorial phase are carried into too warm a temperature, and either move out eastward or westward or ascend mountains. On the latter they can go further south and 
even cross the equator. On the other side of the equator they may come down gradually from the mountains. ... Close investigation always discloses the fact that the original starting point of these migrations was on the Schwingungskreis."

Still another useful function of the Reibisch theory is the explanation of the common arcshaped (Bogenförmig) life-area. This type of distribution is assumed to be due to the effect of the organism's meeting the "Kulminationskreis" in its eastward or westward migration. It should be explained that the Kulminationskreis is a great circle which passes through Ecuador and Sumatra at right angles to the equator, and is so named because it marks the position of nearest approach to the rotational poles that can be attained by any point on the globe's surface during pendulation. In an eastward or westward movement of a species, when the Kulminationskreis is reached, a halt and change of direction is likely to be made, since at this point opposite conditions of climate set in. For example, an organism passing northwestward through that portion of North America lying in the Atlantic-Indic North Quadrant (which is in equatorial phase) enters, when it crosses longitude $80^{\circ}$ west, a quadrant which is in its polar phase. The turn southward follows and the "Bogenförmig Areal" is the result.

Especially interesting is Professor Simroth's very brief discussion of the character of the fauna of the swing-pole regions themselves. Here, where pendulation has been so little as to be practically negligible as an agent of climatic change, we might expect to find the homes of many very ancient forms of life, such as have never experienced the necessity of moving. That a comparison of the faunas of both east and west swing-pole regions with that of extra-polar areas reveals a gratifying number of primitive forms is held to be true by the author. And the existence is asserted of a mass of botanical writings whose purpose has been to establish how little the recent flora of both swing-pole regions differs from that of the Tertiary.

The preceding brief review of the effects on the movements and evolutionary changes in species and faunas that might be expected through the operation of pendulation has been without reference to the effects of the land upheavals and submergences that are a necessary consequence of the pendulation principle. Of these latter and their effects, so largely speculative, little is offered by the author or could be expected. As further examples of equatorial sinkings are mentioned the Caspian area, the Dead Sea, North Africa and North Australia. Such broad low flat areas as the Sahara, in particular, because of their lack of defensive or refuge-furnishing barriers, are believed to have been of high importance as factors in the initiation of evolutionary changes. Animals and plants originating in such a place must make more than ordinary effort to keep in an equable climate. For such pendulation has the mandate: move or vary. In considering the eventuality that some might stay, it is ventured that "only the strongest mutations would suffice" those that did. To those that move several alternatives are open. They may go east or west on their own meridian. If there are mountains, they may ascend them. In a polar movement they may attain greater warmth, perhaps, by voluntarily descending into the sea; while in an equatorial movement which involves a stretch of continent already low, many will be forced into the sea with the gradual submergence.

Estimates of the value of as purely speculative a piece of work as this are so apt to vary with individual temperament or scientific interest that they are little better than gratuitous. When the issue between the author and his public (for the book is confessedly a brief) is so largely one of interpretation, the pointing of minor errors of fact, unavoidable in so great a massing of material from so wide a field, has scant relevance. Beside the conception in defense of which the author's thesis has been written, even a vaster compilation of biological data than Professor Simroth has brought together might well have for many an appearance of comparative insignificance. So it will doubtless be easier for most readers to admit a considerable measure of explaining value in 
the theory, once granted, than to grant it and its retinue of corollary assumptions. But the mere novelty and unfamiliarity of the conception, not to say the strange difficulty that the reader experiences at first in orienting himself in a pendulating world, need hardly of itself invite to indifference or contempt. A hypothesis, however unproven or unprovable, which puts into such new and clear light so many obscure phenomena seems to me to deserve, at least at the hands of students of distribution, a modicum more of attention than has recently been accorded it by a British reviewer. As for the ultimate disposition of such theories as those of Reibisch and Kreichgaur, that is clearly more likely to fall within the province of astrophysics than of faunistic biology.

DEPaRTMENT OF BIONOMICS,

Robert E. Richardson

STANFORD UNIVERSITY

\section{MOREHOUSE'S COMET}

A COMET was discovered photographically at the Yerkes Observatory on the evening of September 1, by Professor D. W. Morehouse, of Drake University, Des Moines, Ia., who has been engaged in graduate work during the summer under the direction of Professor Barnard.

The comet's position on the three plates simultaneously exposed on that night was approximately: R. A. $3^{\mathrm{h}} 20^{\mathrm{m}}$; Dec. North $+66^{\circ}$.

Several photographs were also obtained by Professors Barnard and Morehouse on September 2 and 3, from which quite accurate positions will be determined. The tail is shown on the plates for a length of about six degrees, and exhibits some interesting structure. Although the comet made a strong impression on the discovery plates, it was faint visually when seen on the following night, and was without any definite nucleus. The coma was not large, but was uniformly diffuse.

A micrometric position was obtained with the 12-inch refractor by Mr. Fox, as follows: Sept. 2, G. M. T., $17^{\mathrm{h}} 45^{\mathrm{m}}$, R. A. $=3^{\mathrm{h}} 21^{\mathrm{m}} 55^{\mathrm{s}}$; Dec. $=+66^{\circ} 52^{\prime} 24^{\prime \prime}$.

The motion is thus seen to be toward the north, with a slight westerly component. The comet is of course above the horizon in northern latitudes through the whole night.

EDwin B. Frost

YeRKes OBSERVATORY,

September 4, 1908

\section{SPECIAL ARTICLES}

NOTE UPON THE STRUCTURE OF THE SANTA

\section{CATALINA GNEISS, ARIZONA}

THE extensively-developed pre-Cambrian gneiss of the South side of the Santa Catalina Mountains near Tucson, Arizona, is remarkable for its tabular form; its regular stratification; its altitude at low angles; its broad flat surfaces and in places, for its extreme foliation, passing from coarse grained tabular granitic-gneiss into micaceous, sericitic and hornblende schists. Seen from a distance, especially from the locality known as Gibbon's Ranche, the croppings appear like ordinary stratified sandstones and shales. Close inspection reveals an elongated drawn out and flattened structure, which it is the special object of this paper to note.

The whole series appears to have been elongated under great pressure, resulting in flattening and spreading out into thin layers with a consequent reduction of thickness and an increased lamination.

I purposely refrain from describing this modification of form as a "flow" or as "flowstructure" for these terms convey the impression of a much more mobile condition than existed and of superficial movement rather than of the interior elongation by stretching under great pressure of a deeply seated mass of comparatively solid rock.

The compression and extension are shown in several ways, but specially by the elongation of nodules of feldspar; by sheets of quartz which seem to have been rolled out like dough and impressed by nodular masses of feldspar above and below.

The phenomena remind the observer of the curiously elongated rocks in California; the "grave-stone slates" and sandstones of the middle gold region, which are there uplifted at high angles, while in the Catalina gneiss the dip is gentle, approaching horizontality. 